\title{
Evaluation of Frequency of Congenital Heart Defects in Children of Age Up To 2 Years on Echocardiography
}

\author{
Warda Mehak ${ }^{1 *}$, Narjis Batool ${ }^{2}$, Nosheen Arshad $^{3}$, Nazeeha Waseem $^{4}$, Fatima Arfan ${ }^{5}$, Abid Ali $^{6}$ \\ ${ }_{1,4,5}$ Medical Imaging Doctor, Department of Radiological Sciences and Medical Imaging, University of Lahore, Gujrat, Pakistan \\ ${ }^{2}, 3$ Lecturer, Department of Radiological Sciences and Medical Imaging, University of Lahore, Gujrat, Pakistan \\ ${ }^{6}$ Associate Professor, Department of Allied Health Sciences, University of Lahore, Gujrat, Pakistan
}

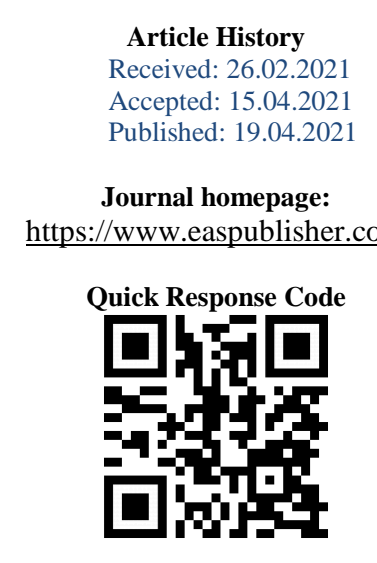

Abstract: Background: Congestive heart failure (CHF) is a persistent, progressive disease that impairs the heart's capacity to pump blood. CHF is the stage in which fluid builds up inside the heart and allows it to move inefficiently. It is also referred to literally as "heart failure." An identification of CHD screening is critical; echocardiography is a non-invasive procedure, and advanced twodimensional echocardiography techniques provide a systematic means to determine nearly all forms of CHD seen in both adults and infants. Objective: The aim of this research is to classify the most common congenital heart defects in children under the age of two who are referred to echocardiography, as well as to confirm the existence of disease on echocardiography at Aziz Bhatti Shaheed Teaching Hospital, Gujrat. Methods: Using Performa, a descriptive-observational analysis was performed at the Department of Cardiology, Aziz Bhatti Shaheed Teaching Hospital, and Gujrat from November 2020-Febury2021. Results: Data of 120 children was evaluated. There were $60 \%$ males $(n=72)$ and $40 \%$ females $(n=48)$. Informed consent was obtained from each patient before inclusion in the study. Echocardiography data was collected on a predesigned Performa. Out of 120 referred children (neonates: $29.9 \%$, less than 1 year: $50.2 \%$, greater than 1 year: 19.9\%) 93\% were diagnosed as having congenital heart defects. Conclusion: Fallot teratology is the most popular cyanotic defect and VSD acyanotic defect. Early diagnosis of congenital heart abnormalities is important for careful treatment and the prevention of complications. The gold norm for diagnosis is a 2D-echo with Doppler test.

Keywords: Teratology of Fallot, Congenital heart defects, Echocardiography, Cyanotic defects.

Copyright (C) 2021 The Author(s): This is an open-access article distributed under the terms of the Creative Commons Attribution 4.0 International License (CC BY-NC 4.0) which permits unrestricted use, distribution, and reproduction in any medium for non-commercial use provided the original author and source are credited.

\section{INTRODUCTION}

Congenital cardiac disorders, also called congenital cardiovascular abnormalities, are anatomical problems triggered by irregular heart or major blood vessel structure during fetal development [3]. CHDs are the most common congenital fetal malformations, accounting for about a quarter of all congenital malformations and carrying a significant risk of child death and morbidity [7]. CHDs may influence people at any age, from birth to adolescence. Two-thirds of disabled infants are reported to be seriously ill in their first year of existence and only a limited proportion of them live to infancy, either by natural selection or effective management or curative surgery [3]. The bulk of cases is asymptomatic and is found through regular physical exams. Cyanosis, joint clubbing, and full- fledged congestive heart failure are some of the symptoms. Its cause is unknown, although it is thought to be multifactorial, with chromosomal abnormalities, maternal diabetes, alcohol, teratogenic drugs, maternal infection in the first trimester, and environmental influences all playing a part [7]. In both developed and emerging nations, congenital heart failure is a major cause of child mortality. The number of babies born with CHD has declined in developing countries as a consequence of prompt clinical abortion, and survival has increased as a result of surgical correction. In comparison, the overwhelming number of patients dies or goes undiagnosed in poor nations where health facilities are inadequate or only open to the wealthy [3]. From the outset; scientific development has been at the disposal of pediatric cardiology growth. One of the 
most revolutionary moments in its development was the inclusion of echocardiography as a standard diagnostic procedure because it allowed for a pictorial recording of the heart's action as well as an understanding of the flow phenomena and hemodynamic consequences that some entities carry [9].

\section{Materials ANd Method}

A descriptive-Observational study was carried out at Department of Cardiology Aziz Bhatti Shaheed Teaching Hospital, Gujrat during the period from November 2020-Febury2021 through Performa.

\section{Inclusion Criteria}

All patients up to 2 years of age presented in Cardiology department for echocardiography of both male and female genders were included in this study.

\section{Exclusion Criteria}

All patients above 2 years of age presented in cardiology department for echocardiography were excluded in this study.

\section{Data Analysis}

The patients of CHDs were studied by entering the required data on a detailed Performa. The data was displayed in charts, graphs, and pie diagrams, and it was evaluated with the Statistical Kit for the Social Sciences (SPSS) program version 20.

\section{RESUlTS}

To evaluate the frequency of congenital heart defects in infants and young children data of 120 children was evaluated. There were $60 \%$ males $(n=72)$ and $40 \%$ females $(n=48)$. Informed consent was obtained from each patient before inclusion in the study. Echocardiography data was collected on a predesigned Performa. Out of 120 referred children (neonates: $29.9 \%$, less than 1 year: $50.2 \%$, greater than 1 year: 19.9\%) $93 \%$ were diagnosed as having congenital heart defects. The relative frequencies of cyanotic and acyanotic congenital heart defects were $17 \%, 83 \%$ (figure 1.1). The most prominent acyanotic congenital heart defects is Ventricular septal defect $(33.3 \%)$, atrial septal defect $(10.8 \%)$, and Patent ductus atriosus $(22.5 \%)$. The most frequent cyanotic congenital heart abnormality is Tetralogy of Fallot (6.6\%), Transposition of Great Arteries (5.7\%), and Tricuspid Atresia (2.5\%). Table 1.1 shows the approximate frequency of congenital heart abnormalities.

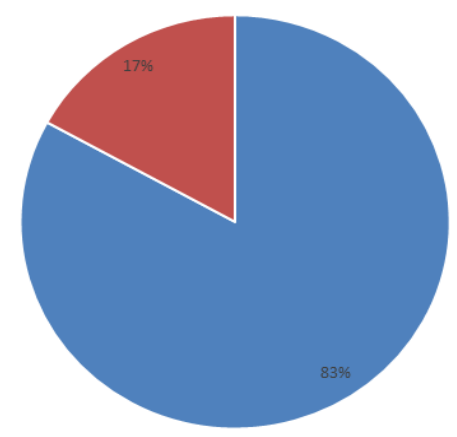

- Acyanotic heart defects . Cyanotic heart defects

Fig-1.1: Pie chart representing the relative percentages of cyanotic and acyanotic heart defects

Table-1.1: The relative frequencies of congenital heart defects in infants and young children

\begin{tabular}{|l|l|l|}
\hline Disease & $\begin{array}{l}\text { Frequency } \\
(\mathbf{n})\end{array}$ & $\begin{array}{l}\text { Percentage } \\
(\mathbf{\%})\end{array}$ \\
\hline Atrial Septal Defect & 13 & 10.8 \\
\hline $\begin{array}{l}\text { Ventricular Septal } \\
\text { Defect }\end{array}$ & 40 & 33.3 \\
\hline $\begin{array}{l}\text { Patent Ductus } \\
\text { Arteriosus }\end{array}$ & 27 & 22.5 \\
\hline Coarctation of Aorta & 5 & 4.1 \\
\hline Tetralogy of Fallot & 8 & 6.6 \\
\hline $\begin{array}{l}\text { Transposition of } \\
\text { great Arteries }\end{array}$ & 7 & 5.8 \\
\hline Tricuspid Atresia & 3 & 2.5 \\
\hline Ebstein's Anomaly & 3 & 2.5 \\
\hline Truncus Arteriosus & 3 & 2.5 \\
\hline $\begin{array}{l}\text { Pulmonary valve } \\
\text { stenosis }\end{array}$ & 6 & 5 \\
\hline C-AVSD & 2 & 1.6 \\
\hline OTHERS & 3 & 2.5 \\
\hline
\end{tabular}

Others: DORV, DC, Hypertrophied IVS, PH, MR, MS, $\mathrm{AR}$ and $\mathrm{AS}$

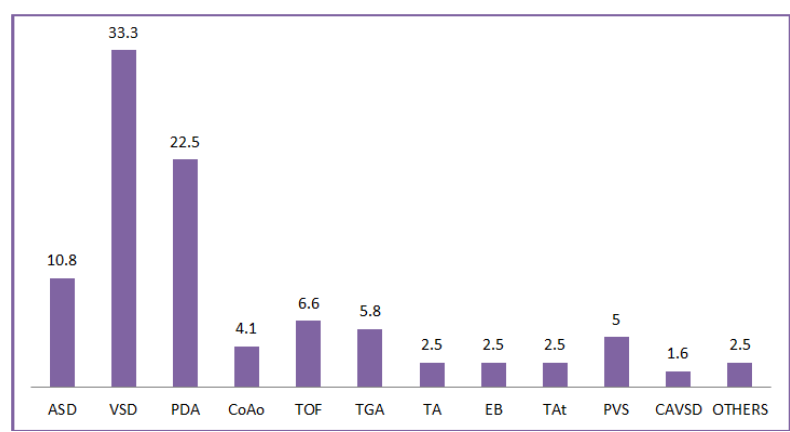

Fig-1.2: Simple bar chart representing the most frequent congenital heart defects in infants and young children

Others: DORV, DC, Hypertrophied IVS, PH, MR, MS, $\mathrm{AR}$ and $\mathrm{AS}$ 


\section{DiscussiON}

The current study found that acyanotic congenital heart diseases were more common than cyanotic CHDs. The relative frequencies of cyanotic CHDs and acyanotic CHDs were $17 \%$, and $83 \%$ respectively. This well correlated with other studies. The relative frequencies of most frequent ayanotic diseases were VSD $33.3 \%$, PDA $22.5 \%$, and ASD $10.8 \%$. The relative frequencies of most frequent cyanotic diseases were TOF $6.6 \%$, TGA $5.9 \%$ and TA $2.5 \%$.

The most common acyanotic defect in our study was ventricular septal defect, which had a 33.3 percent prevalence. This was comparable to the findings of another analysis performed in Belgium2, and the incidence was smaller than Jordan7's recorded incidence of $48.4 \%$, but higher than Turkey1's reported incidence of 22.8 percent. The discrepancies in our statistics and those in the literature may be attributed to reasons such as the universal standard in diagnosis, the pause in diagnosing VSDs causing more VSDs to close spontaneously, the physician accountable for primary care's inability to identify minimum or minor septal defects, and the short length of my research.

Another typical defect that occurs more often in preterm babies is patent ductus arteriosus (PDA). PDA was the second most prevalent acyanotic defect found in children's hospitals and FIC in the current report, accounting for 22.3 percent of the children. Similar other studies were conducted in Turkey, Yemen and Jordan with resulting frequency of PDA $17.1 \%$, $17.3 \%$ and $8.3 \%$ respectively $[1,3,7]$. The reason for the increase in frequency of PDA may be due to the high rate of preterm deliveries.

The third most frequent acyaontic heart defect was atrial septal defect in frequency accounting (10.7\%) in our study. According to the results of other studies that were conducted in Turkey, Yemen \& Jordan the resulting frequency of ASD are 20\%, 15.8\% and $13.6 \%$ respectively. The frequency of ASD is more likely to be less than other studies performed because our study criteria was the age group up to 2 years and the fact that ASDs are asymptomatic in childhood. ASD is typically asymptomatic, with soft murmurs. Sometimes, these weaknesses go undetected before it's too late. As a consequence, all of these events show themselves in adulthood.

Tetralogy of Fallot was the first common cyanotic congenital heart disorder, followed by transposition of the great arteries as the most common cyanotic congenital heart disease (5.8 percent).

According to the result of other studies that were conducted in Yemen, Jordan and Naibori the resulting frequencies of TOF and TGA were $(8.9 \%$, $3.1 \%),(9.5 \%, 5.5 \%)$, and $(10.7 \%, 8.4 \%)$ respectively.
The result of TOF and TGA were different from other literature studies due to limited time, limited sample size and specific inclusion criteria of my study.

\section{CONCLUSION}

Finally, this study offers a description of the congenital heart disorder trend at Aziz Bhatti Shaheed Teaching Hospital, Gujrat. Acyanotic congenital cardiac abnormalities are present in the overwhelming majority of people with congenital heart disease. TOF is the most common cyanotic defect, and VSD is the most common acyanotic defect. Early diagnosis of congenital heart abnormalities is important for careful treatment and the prevention of complications. The gold norm for diagnosis is a 2D-echo with Doppler test.

\section{ACKNOWLEDGEMENTS}

Authors would like to thank patients for their adherence and kind cooperation in current study and the staff and technicians of the hospital for performing the different tests required for the study.

\section{Ethical Consideration}

Confidentiality of information was ensured.

No ethical issue regarding topic of study as the study was completely observational.

Funding: No funding sources

Conflict of interest: None declared

\section{REFERENCES}

1. Korkmaz, U. K., Ozkan, E. A., Akkoca, A. N., \& Sivaslioglu, E. (2015). Incidence and Clinical Characteristics of Congenital Heart Disease among Neonates in Neonatal Intensive Care Unit. American Journal of Health Research, 3(3), 161-165.

2. Moons, P., Sluysmans, T., De Wolf, D., Massin, M., Suys, B., Benatar, A., \& Gewillig, M. (2009). Congenital heart disease in 111225 births in Belgium: birth prevalence, treatment and survival in the 21 st century. Acta paediatrica, 98(3), 472477.

3. Saleh, H. K. (2009). Pattern of congenital heart disease in Southern Yemeni children referred for echocardiography. Saudi medical journal, 30(6), 824-828.

4. Khalil, A., Aggarwal, R., Thirupuram, S., \& Arora, R. (1994). Incidence of congenital heart disease among hospital live births in India. Indian pediatrics, 31(5), 519-528.

5. Awori, M. (2013). The spectrum of paediatric congenital heart disease at the Kenyatta National Hospital: Implications for surgical care. Annals of African Surgery, 10(1).

6. Miyague, N. I., Cardoso, S. M., Meyer, F., Ultramari, F. T., Araújo, F. H., Rozkowisk, I., \& 
Toschi, A. P. (2003). Epidemiological study of congenital heart defects in children and adolescents: analysis of 4,538 cases. Arquivos brasileiros de cardiologia, 80(3), 274-278.

7. Amro, K. (2009). Pattern of congenital heart disease in Jordan. Eur J Gen Med, 6(3), 161-165.

8. Ashraf, M., Chowdhary, J., Khajuria, K., \& Reyaz, A. M. (2009). Spectrum of congenital heart diseases in Kashmir, India. Indian pediatrics, 46(12).

9. Miranović, V. (2014). The incidence of congenital heart disease: previous findings and perspectives. Srpski arhiv za celokupno lekarstvo, 142(3-4), 243-248.

10. Thomas, M. O., Olusoji, O., \& Awolola, N. (2013). Spectrum of congenital heart diseases in an African population: A necropsy study.

11. Ekwere, E. O., McNeil, R., Agim, B., Jeminiwa, B., Oni, O., \& Pam, S. (2011). A retrospective study of congenital anomalies presented at tertiary health facilities in Jos, Nigeria. Journal of Physics: Conference Series (JPCS).
12. Hoffman, J. I., \& Kaplan, S. (2002). The incidence of congenital heart disease. Journal of the American college of cardiology,39(12), 18901900.

13. Karbasi, S. A., Golestan, M., Fallah, R., Mirnaseri, F., Barkhordari, K., \& Bafghee, M. S. (2009). Prevalence of congenital malformations. Acta Medica Iranica, 149-153.

14. Morocutti, A., Saeed, S., \& Doria, A. (2010). Incidence of congenital heart diseases, 5: 313-319.

15. Danish, M.I. (2012). Short textbook of Medical Diagnosis and management. 9th ed., Krachi Pakistan, Johar.

16. Ryan, S., McNicholas, M., \& Eustace, S. (2011). Anatomy for Diagnostic Imaging. 3th ed., New York, Saunders.

17. Dorland, W.A.N. (2011). Dorland's Illustrated Medical Dictionary online. 32th ed., New York, Saunders.

18. Kaddoura, S. (2009). Echo Made Easy. 2th ed., London, Livingstone.

Cite This Article: Warda Mehak et al (2021). Evaluation of Frequency of Congenital Heart Defects in Children of Age Up To 2 Years on Echocardiography. EAS J Radiol Imaging Technol, 3(2), 69-72. 